\title{
The Annealing Effect of Zinc Selenide Thin Film Using CBD Technique for PV Solar Cell Application
}

\author{
M. Kavitha*, M. Saroja, G. Jenifer \\ Department of Physics, the Madura College,Madurai-11, TamilNadu. \\ * Corresponding author. Tel.: 9976033732; email: kavirmk@yahoo.com \\ Manuscript submitted January 11, 2017; accepted July 7, 2017. \\ doi: 10.17706/ijmse.2017.5.3.110-115
}

\begin{abstract}
ZnSe thin films have been successfully deposited the different temperatures on an FTO substrate by using chemical bath deposition (CBD) technique. The chemical baths include the solutions of zinc acetate, Thiourea, selenium and deionizer water. The deposition parameters such as $\mathrm{pH}$ of the bath; deposition time, temperature etc. are optimized. As annealing temperature increased $200{ }^{\circ} \mathrm{C}$, the film was increased due to the coalescence of the nature due to crystalline given by the thermal energy occurring in the heating treatment of the film. The sizes of the grains are noticed to enhance at the same time as the temperature better too without annealing $(200 \mathrm{~nm})$ and with annealing $(1 \mu \mathrm{m})$ fully covered on the substrate. The proportion of the constituent elements measured for before annealing is lower than the after annealing of FTO substrate. The optical absorbance of thin film samples was measured by DRS-UV spectroscopy within wavelength range of 300-1100 $\mathrm{nm}$. The absorption spectra for the $\mathrm{ZnSe}$ thin film are analyzed, before annealing maximum absorption coefficient $(\mathrm{k})$ is $402 \mathrm{~cm}^{-1}$ and after annealing maximum absorption (k) is $489 \mathrm{~cm}^{-1}$. Using the optical parameter, refractive index (n) of the ZnSe thin film with annealing is determined as 1.76 and without annealing is 2.45 , the thickness $(\mathrm{t})$ of the ZnSe thin film with annealing is $249 \mathrm{~nm}$ and without annealing is $87 \mathrm{~nm}$ and also found that the optical energy band value before annealing $2.48 \mathrm{eV}$ and after annealing $2.02 \mathrm{eV}$. J-V performance of solar cells is reported. The efficiency of the ZnSe thin film is found to increase compared to the without annealing. It will be identified ZnSe thin film deposited by low cost technique and their physical properties are estimated as a possible mechanism for high efficiency.
\end{abstract}

Keywords: ZnSe thin film, CBD, SEM and EDAX, DRS-UV and J-V studies.

\section{Introduction}

Concentrator photovoltaic's (CPV) is a photovoltaic technology that, contrary to conventional flat-plate PV systems uses lenses and curved mirrors to focus sunlight onto small, but highly efficient, multi-junction (MJ) solar cells. In addition, CPV systems often use solar trackers and sometimes a cooling system to further increase their efficiency. Ongoing research and development is rapidly improving their competitiveness in the utility-scale segment and in areas of high solar insolation [1]-[4]. (ZnSe) mostly used in photovoltaic, photo catalysis, UV blue emitting diodes, photo electrochemical properties, photo luminescence etc.. The (ZnSe) thin films were prepared by the chemical methods. In this present work, the ZnSe films are coated on the FTO substrate and maintained at bath temperature $65^{\circ} \mathrm{C}$ followed by pH $9-10$ for the composition using the chemical bath technique. The samples were annealed at $200^{\circ} \mathrm{C}$ and characterization was done to study the Morphological, Optical properties. J-V studies are also carried out by the linear sweep voltametry 
Galvanostatic [5]-[9] .

\section{Experimental}

Zinc Selenide (ZnSe) thin films were grown on an FTO glass substrate using the Chemical bath deposition technique. The substrate is mounted on a plastic holder and the solution is continuously stirred at a constant 600 RPM during the deposition. The bath temperature was controlled by a hot plate. In order to obtain good adherence and uniformity for the film, firstly the FTO glass substrate was cleaned with acetone in addition to diluted hydrochloric solution and then washed with deionizer water and finally dried with air. The standard procedure was followed in the direction of the deposit $\mathrm{ZnSe}$ thin film. The deposition bath consists of aqueous solution of $50 \mathrm{ml}(0.2 \mathrm{M})$ Zinc acetate, $50 \mathrm{ml}(0.2 \mathrm{M})$ of Thiourea is completely dissolved in distilled water. Now the chemical bath solution was placed in a glass beaker and controlled at the temperature $65^{\circ} \mathrm{C}$. Then $1 \mathrm{gm}$ of selenium (Se) was dissolved in $20 \mathrm{ml}$ of nitric acid completely dissolved as well as selenium (Se) is added. Then the $\mathrm{pH}$ value of the prepared solution was adjusted during the deposition by using the ammonia solution $\left(\mathrm{NH}_{3}\right)$ and kept the value of 9-10. During the deposition of bath solution was stirred, the growth time was 300 mints. (5hrs).At the end of deposition process the substrate was removed from chemical bath and then cleaned with acetone. The prepared samples were annealed at $200^{\circ} \mathrm{C}$. The observed film was uniform and it has very good adhesion [10], [11].

\section{Results and Discussions}

\subsection{Optical Properties}

The semiconductor with direct band gap follows the relationship $\alpha \mathrm{h} v=\mathrm{A}(\mathrm{h} v-\mathrm{Eg}) \wedge 1 / 2$ for $\mathrm{h} v>\mathrm{Eg}$, where $\alpha$, $\mathrm{h} v, \mathrm{Eg}, \mathrm{A}$ are the absorption coefficient, photon energy, optical band gap and proportionality constant respectively. The optical properties of the ZnSe thin film with and without annealing are observed from the DRS-UV spectrum. The DRS absorption spectra of ZnSe thin film within the range of 300nm -1100 nm as shown in Fig. 1. The optical absorption edge is approximately located on the corresponding wavelength. In absorption spectra was found that the $(\alpha \mathrm{h} v)^{\wedge} 2$ is plotted aligned with $\mathrm{h} v$ for both the films. The straight line of the plot is extrapolated to zero absorption $\left\{(\alpha h v)^{\wedge} 2=0\right\}$ in order to obtain the band gap as shown in Fig. 2 .The absorption spectra for the ZnSe thinfilm are analyzed, before annealing maximum absorption coefficient (k) is $422 \mathrm{~cm}^{-1}$ and after annealing maximum absorption co-efficient(k) is $479 \mathrm{~cm}^{-1}$ [12]. Using reflectance and transmittance, determined the refractive index (n) of the ZnSe thinfilm with annealing is 1.76 and without annealing is 2.45 , the thickness of the film $(t)$ with annealing is $259 \mathrm{~nm}$ and without annealing is $89 \mathrm{~nm} \mathrm{[13]} \mathrm{and} \mathrm{also} \mathrm{found} \mathrm{that} \mathrm{the} \mathrm{optical} \mathrm{energy} \mathrm{band} \mathrm{gap} \mathrm{(Eg)} \mathrm{value} \mathrm{before} \mathrm{annealing} 2.49 \mathrm{eV}$ and after annealing $2.02 \mathrm{eV} \mathrm{[14]-[16].} \mathrm{The} \mathrm{results} \mathrm{are} \mathrm{tabulated} \mathrm{as} \mathrm{shown} \mathrm{in} \mathrm{the} \mathrm{Table} 1$.

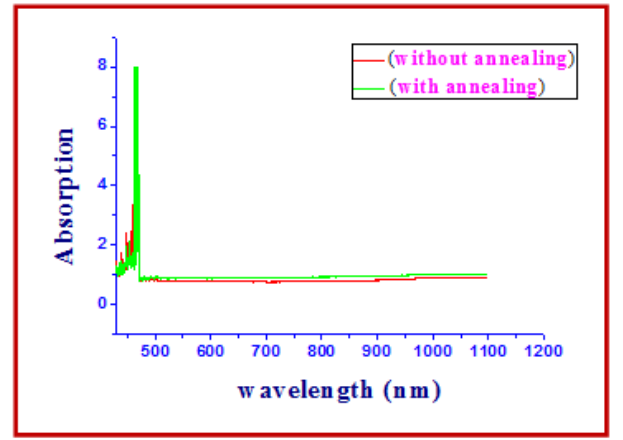

Fig.1. Absorption spectrum for without and with annealing of ZnSe thin films. 


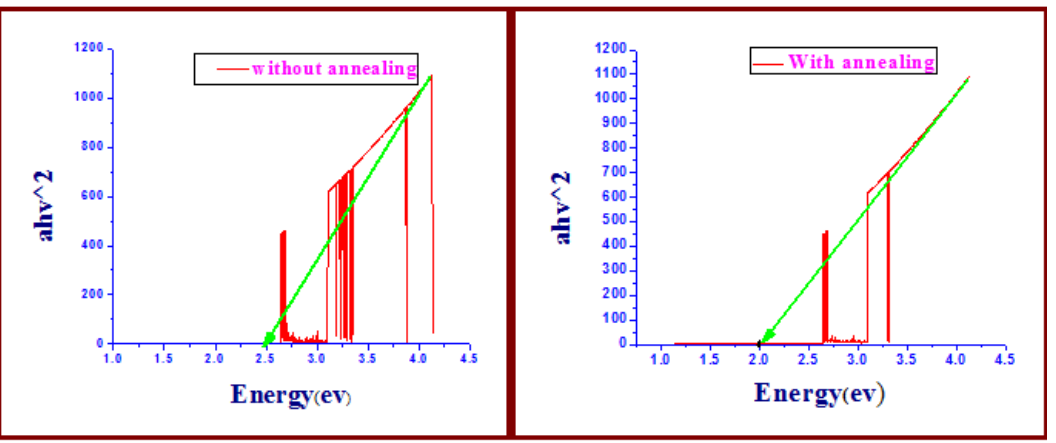

Fig. 2. Energy spectrum for without and with annealing of ZnSe thin films.

Table 1. Optical Parameters of ZnSe Thin Films

\begin{tabular}{|c|c|c|c|c|}
\hline Sample & $\begin{array}{c}\text { Absorption } \\
\text { coefficient (k),(cm) }\end{array}$ & $\begin{array}{c}\text { Thickness of the } \\
\text { film (t) (nm) }\end{array}$ & $\begin{array}{c}\text { Refractive } \\
\text { index (n) }\end{array}$ & $\begin{array}{c}\text { Energy Gap (Eg) } \\
\text { (eV) }\end{array}$ \\
\hline $\begin{array}{c}\text { Without annealing } \\
\text { (FTO) }\end{array}$ & 402 & 87 & 2.45 & 2.48 \\
\hline $\begin{array}{c}\text { With annealing } \\
\text { (FTO) }\end{array}$ & 489 & 249 & 1.76 & 2.02 \\
\hline
\end{tabular}

\subsection{Morphological and Elemental Analysis}

The scanning electron microscopy (SEM) and energy dispersive analysis of X- ray spectroscopy (EDAX) studies are carried out. ZnSe thin film, we employed for without annealing and with annealed $\left(200^{\circ} \mathrm{C}\right)$ films at instance duration 60 min as shown in Fig. 3(a) and 3(b). The SEM micrographs of the films deposited for normal and $200^{\circ} \mathrm{C}$ show the distribution of grains, which covers the surface of the substrate completely [17]. No pinholes could be detected on the surface of these thin films. The closely packed grains provide a pinhole free morphology, which could lead to better spatial contact between the grains, which is desirable for use in photoelectrochemical cells. These films also show agglomerated structure and exhibit well-defined grain edges compared to the film deposited for without and with annealing $\left(200^{\circ} \mathrm{C}\right)$ as well. This uniform structure, grain with small pinhole on the surface. Before annealing the formation adhesion nature and smooth plane surface. As annealing temperature increased $200{ }^{\circ} \mathrm{C}$, the film was increased due to the coalescence of the nature due to crystalline given by the thermal energy occurring in the heating treatment of the film. The film deposited on the substrate depends on the formation nucleation site and subsequent growth of the films from these centers. The sizes of the grains are noticed to enhance at the same time as the temperature better too without annealing $(200 \mathrm{~nm})$ and with annealing $(1 \mu \mathrm{m})$ fully covered on the substrate. From the EDAX spectra the elements are analyzed as shown in Table 2. The table lists the atomic ratio of the zinc selenide thin films prepared under different temperature. The composition analysis enabled to confirm that to prepared before and after annealing the ZnSe thin film samples are determined [18].

\subsection{J-V Studies}

The photovoltaic performance test of test of ZnSe thin film was calculated by measuring J-V characteristic curve as shown in the Fig. 4 by using linear sweep voltametry Galvanostatic (PGSTAT302N) meter by using short circuit current density (Jsc) and open circuit voltage (Voc) under the illumination condition (AM1.5, $1000 \mathrm{~W} / \mathrm{m}^{2}$ ) as seen in the Table 3. The J - V Graph as shown in the Fig. 4. The intensity of solar radiation has covered the region in $2 \mathrm{~cm}^{2}$ was calculated in the fill factor and also determined the conversion efficiency. Table 3 indicates $\mathrm{J}-\mathrm{V}$ parameter of the multilayer thin film solar cell gave a short circuit current density $\mathrm{JSC}_{\mathrm{SC}} \mathrm{V}_{\mathrm{OC}}$ open circuit voltage and the fill factor of and reporting the conversion efficiency. The graph 
indicates that the maximum power conversion efficiency has gradually been varied when compared to the with and without annealing. The open circuit voltage (Voc) of the ZnSe thin film with annealing the potential was increased as compared to without annealing. The photo generated charge carrier's increases with increasing in the power[19].

Table 2. Elemental Analysis

\begin{tabular}{|c|c|c|c|c|}
\hline \multirow{2}{*}{ Element } & \multicolumn{2}{|c|}{ Without annealing } & \multicolumn{2}{c|}{ With annealing (200 $\mathbf{C})$} \\
\cline { 2 - 5 } & Normal (Wt \%) & Atomic (Wt \%) & Normal (Wt \%) & Atomic (Wt \%) \\
\hline Zn & 36.59 & 30.27 & 43.57 & 47.71 \\
\hline Se & 19.43 & 24.17 & 38.31 & 23.84 \\
\hline Oxygen & 0.08 & 0.47 & - & - \\
\hline Tin & 0.32 & .04 & - & - \\
\hline Molybdenum & 43.58 & 44.61 & - & - \\
\hline Sulfur & - & - & 17.13 & 20.44 \\
\hline Total & 100 & 100 & 100 & 100 \\
\hline
\end{tabular}
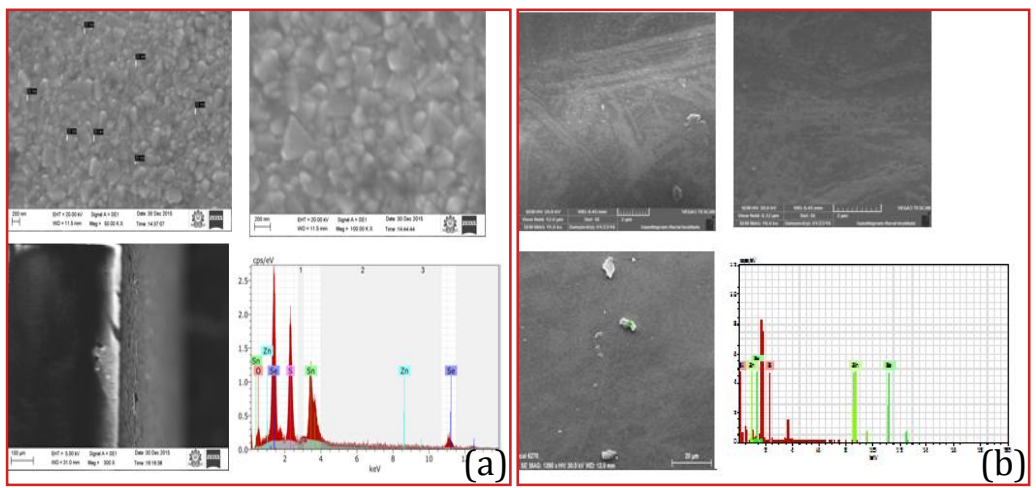

Fig. 3. (a) \& (b). The surface and cross sectional image of without and with annealing of ZnSe thin films.
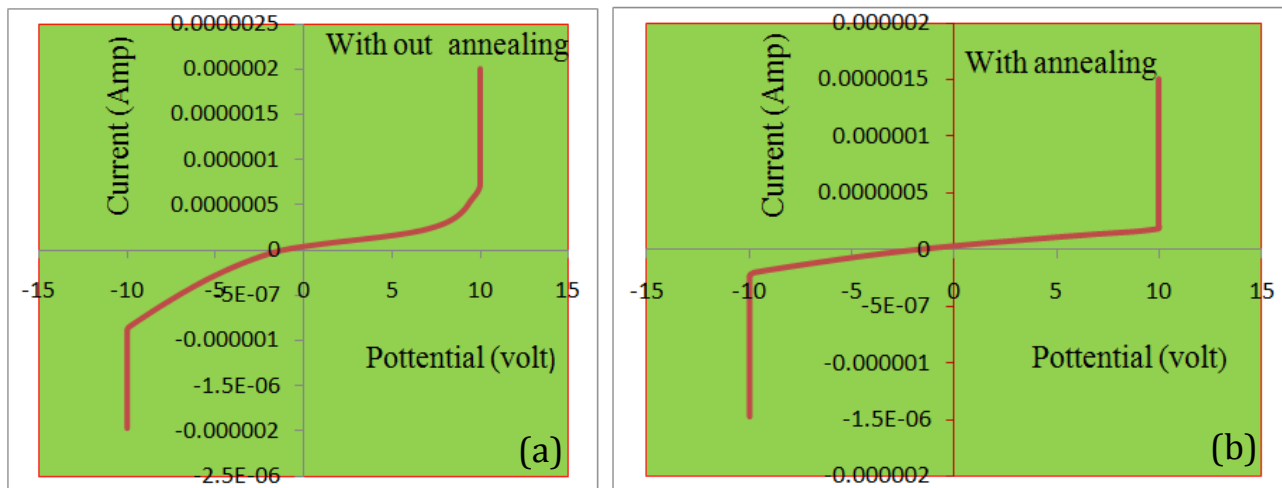

Fig. 4. (a) and (b). J-V characteristics in without annealing and with annealing of ZnSe thin films.

Table 3. J-V Parameters of ZnSe Thin Films

\begin{tabular}{|c|c|c|c|c|c|}
\hline Sample & $\begin{array}{c}\text { Area } \\
\left(\mathrm{cm}^{2}\right)\end{array}$ & $\begin{array}{c}\text { Open circuit Voltage } \\
(\text { Voc })(\mu \mathrm{V})\end{array}$ & $\begin{array}{c}\text { Short circuit } \\
\text { current }(\mathrm{Jsc})(\mu \mathrm{A})\end{array}$ & $\begin{array}{c}\text { Fill factor } \\
(\%)\end{array}$ & $\begin{array}{c}\text { Efficiency } \\
(\eta)(\%)\end{array}$ \\
\hline $\begin{array}{c}\text { Without } \\
\text { annealing (FTO) }\end{array}$ & $2 \times 2$ & 9.76 & 9.125 & 57 & 2.4 \\
\hline $\begin{array}{c}\text { With annealing } \\
\text { (FTO) }\end{array}$ & $2 \times 2$ & 11 & 4.81 & 66 & 5.5 \\
\hline
\end{tabular}




\section{Conclusion}

The preparation of ZnSe thin films using CBD method and prepared thin film samples were characterized using advanced sophisticated instrumentation. The thin film PV solar cell is a review of ZnSe thin film before and after annealing at $200^{\circ} \mathrm{C}$ is presented. The morphological characterization of ZnSe thin film has been studied using SEM instrument. This uniform structure, show the grain of small pinholes on the surface. Before annealing the formation of adhesion nature and smooth plane surfaces are seen. After annealing coalescence nature and smooth plane surface of the film. From the EDAX spectra, the elements are identified before and after annealing the ZnSe thin films. The optical properties of ZnSe with $\left(200^{\circ} \mathrm{C}\right)$ and without annealing of thin films are studied. The absorption, transition and reflection spectra are shown and evaluated the optical parameters. J-V performance of solar cells is reported the efficiency of the $\mathrm{ZnSe}$ thin film is found to increase compared to the without annealing. The PV material subjects of intense interest during these periods. The reviews will be identified ZnSe thin film deposited by low cost technique and their physical properties are estimated possible mechanism for identified the several conditions of the material search and extensive.

\section{References}

[1] Goswami, A. (1996). Thin Film Fundamentals. New Delhi: New Age International Pvt. Ltd.

[2] Soundeswaran, S., Kumar, O. S., Dhanasekaranm, R., Ramasamy, P., Kumaresen, R., \& Ichimura, M. (2003). Growth of ZnSe thin films by electro crystallization technique. Materials Chemistry and Physics, 82(2), 268-272.

[3] Chanrdamohan, R., Kathalingam, A., Kumar, K., Kalyanaraman, D., \& Mahalingam, T. (2004). Studies on Electro synthesized Semiconducting ZincSelenide Thin Film. Ionics, 10(3-4), 297-299.

[4] Dona, J. M., \& Herero, J. (1995). Chemical-bath deposition of ZnSe thinfilms: process and material characterization. J. Electrochemist. Soc., 142(3), 764-770.

[5] Chopra, K. L., \& Das, S. R. (1983). Thin Film Solar Cells. New York: Pletinum Press.

[6] Yang, C. S., Hsieh, Y. P., Kuo, M. C., Tseng, P. Y.,. Yeh, Z. W., Chiu, K. C., et al. (2003). Compressive strain induced heavy hole and light hole splitting of $\mathrm{Zn}_{1-\mathrm{x}} \mathrm{Cd}_{\mathrm{x}} \mathrm{Se}$ epilayers grown by molecular beam epitaxy. Materials Chemistry and Physics, 78(3), 602-607.

[7] Mokili, B., Charreire, Y., Cortes, R., \& Lincot, D. (1996). Extended X-Ray absorption fine structure studies of zinc hydroxo-sulphide thin films chemically deposited from aqueous solution. Thin Solid Films, 288(1-2), 21-28.

[8] Thutupalli, G. K. M., \& Tomlin, S. G. (1976). The optical properties of thin films of cadmium and zinc selenides and tellurides. Journal of Physics D: Applied Physics, 9(11), 1639-1646.

[9] Kuzel Jr, R., Valvoda, V., Chladek, M., Musil, J., \& Matous, J. (1995). XRD microstructural study of Zn films deposited by unbalanced magnetron sputtering. Thin Solid Films, 263(2), 150-158.

[10] Ismaiel, B. B., \& Gold, R. D. (1989). Structural and electrical properties of evaporated thin films of cadmium tellu-ride. Physical Status Solid A, 115(1), 237-245.

[11] Balasubramanian, A. K., Sankar, N., Ramakrishnan, S. K., \& Ramachandran, K. (2004). Thermal conductivity of ZnSe by molecular dynamics simulation. Crystal Research and Technology, 39(6), 558563.

[12] Bang, J., Park, J., Lee, J. H., Won, N., Nam, J., \& Lim, J. (2010). ZnTe/ZnSe (core/shell) type-II quantum dots: Their optical and photovoltaic properties. Chemistry of Materials, 22(1), 233-240. 
[13] El Sherif, M., Terra, F. S., \& Khodier, S. A. (1996). Optical characterizers of thin ZnSe films of different thicknesses. Journal of Materials Science: Materials in Electronics, 7(6), 391-395.

[14] Meulenkamp, E. A. (1998). Synthesis and growth of ZnO nanoparticles. J. Physical Chemistry B. 102(29), 5566-5572.

[15] Erb, U., Palumbo, G., Zugic, R., \& Aust, K. T. (1996). Proceedings and Properties of Nanocrystalline Materials (p. 9). Warrendale, PA: TMS.

[16] Glocker,D. A., \& Shah, S. I. (2002). Handbook of Thin Film Process Technology. Institute of Physics Publishing.

[17] West, A. R. (2003). Solid State Chemistry. Singapore: John Willy \& Sons.

[18] Bach, H., \& Krause, D. (2003). Thin Films on Glass. New York: Springer-Verlag Berlin Heidelberg.

[19] Bunshah, R. F. (1994). Handbook of Deposition Technologies for Films and Coatings (2nd ed.). Noyes Publication.

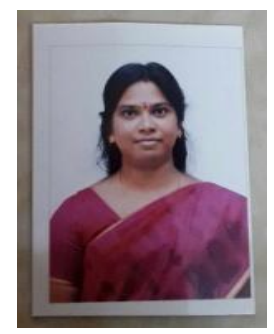

Kavitha M. have completed a Ph.d degree in pv solar cell materials. Her research experience in this field for past five years and also more than 10 years teaching experience in the solar field. She has published 12 papers in international journals and 3 papers presented in international conferences. At present, She is working as Assistant Professor of physics in The Madura College, Madurai. 